\title{
Trump's covid-19 treatment: Can we offer it to other patients in the world
}

\author{
Aamir Jalal Al Mosawi \\ ${ }^{1}$ Advisor in Pediatrics and Pediatric Psychiatry, Children Teaching Hospital of Baghdad Medical City. \\ ${ }^{2} \mathrm{Head}$, Iraq Headquarter of Copernicus Scientists International Panel, Baghdad, Iraq. \\ *Corresponding Author: Aamir Jalal Al Mosawi, 1Advisor in Pediatrics and Pediatric Psychiatry, Children Teaching Hospital of Baghdad \\ Medical City, Head, Iraq Headquarter of Copernicus Scientists International Panel, Baghdad, Iraq. \\ Received date: February 08, 2021; Accepted date: February 19, 2021; Published date: February 25, 2021 \\ Citation: Aamir Jalal Al Mosawi. (2021) Trump's covid-19 treatment: Can we offer it to other patients in the world. Journal of Clinical and \\ Laboratory Research. 2(2) DOI: 10.31579/2768-0487/008
}

Copyright: (C2021 Aamir Jalal Al Mosawi. This is an open-access article distributed under the terms of the Creative Commons Attribution License, which permits unrestricted use, distribution, and reproduction in any medium, provided the original author and source are credited.

\begin{abstract}
Background: Covid-19 is a viral illness caused by severe acute respiratory syndrome coronavirus 2 (SARS-CoV-2). The disease was first reported during December, 2019, in Wuhan, Hubei in China. On Thursday, the first of October 2020, the White House of the USA declared that the president of the USA, Donald Trump had a positive test for SARSCoV-2. He initially had mild symptoms which included mostly, hoarseness, lethargy, and fatigue. The treatment received by a patient "Donald Trump" who was considered the most powerful person in the world is studied, and this paper assumed that all the patients in the world are as important as Mr. Trump and tries to offer the best evidencetreatment for them.
\end{abstract}

Patients and methods: Most media including the CNN television channel rightly confirmed that Mr. Trump has been treated by the best doctors in the world with best therapies that could possibly help him in defeating the virus. The $\mathrm{CNN}$, in various programs during the first week of October, emphasized that, American citizens with Covid-19 are not receiving the same treatments as their president Donald Trump.

Results: Trump aged 74 years and initially had mild symptoms which included mostly, hoarseness, lethargy, and fatigue. His age, obesity and mildly elevated cholesterol were considered risk factors that may reduce the likelihood of having very favorable outcome. It was reported that he initially took hydroxychloroquine, an anti-malarial drug. The use of a therapeutic approach including experimental antibody therapy, remdesivir and dexamethasone has not been reported as a treatment for one patient before other than Mr. Trump. Obviously, of the three important therapies, only dexamethasone can be offered to almost all the patients with covid-19.

Conclusion: It seems that, the most important factors that made treatment of Donald Trump effective and successful are:

1-The early institution of therapy regardless of the generally accepted recommendations.

2-The use of multiple drugs as none of the available drug alone can guarantee successful treatment.

Keywords: Trump's covid-19; evidence-based therapies; medical ethics

\section{Introduction}

Covid-19 is a viral illness caused by severe acute respiratory syndrome coronavirus 2 (SARS-CoV-2). The disease was first reported during December, 2019, in Wuhan, Hubei in China [1, 2, 3].

There are four genera of coronaviruses including alpha-coronaviruses, beta-coronaviruses, gamma-coronaviruses, and delta -coronaviruses. Alpha and beta-coronavirus can infect mammals, while gammacoronavirus and delta-coronavirus generally infect birds.

Four coronaviruses are known to cause mild upper respiratory infection in humans of all ages including infants. The transmission of coronaviruses from animals (birds) to causes respiratory illness has been reported as early as 1969 by Kapikian et al. Community-wide outbreak associated with 229E-like coronavirus has be reported as early as 1970 by Cavallaro and Monto. Until December, 2020, two beta-coronaviruses (SARS coronaviruses and MERS-coronaviruses were known to cause severe, potentially fatal pneumonia-like illness [1-6].

Errors in the replication of viral genomic RNA of zoonotic coronaviruses led to the emergence of genetically related diverse quasi-species, while the transmission of some of them to a new host species led to the emergence of human severe acute respiratory syndrome coronavirus (SARS-CoV) and Middle East respiratory syndrome coronavirus (MERS$\mathrm{CoV})$. SARS-CoV emerged for the first time in Guangdong China in 2002 spread rapidly to many other counties causing more than 8000 cases with about $10 \%$ mortality. In 2012, it was thought that MERS-CoV was 
transmitted to humans from bats through an intermediate camel host leading to 1700 cases in 27 countries with about $40 \%$ mortality [1-6].

The disease has rapidly became a worldwide pandemic, and according to the live online update available at https:// www.worldometers.info/coron avirus/, on the $6^{\text {th }}$ of October, 2020, The disease affected more than 35.5 million person throughout the world, and was associated with more than 1.04 million deaths. In a country like Iraq, many doctors died from covid19 and persons whom were considered to be healthy and possibly having a good immunity like former football players and a bodybuilding champion [7]

The incubation period of the disease is from one day to fourteen days. The disease is commonly associated with fever, cough, fatigue, shortness of breath or breathing difficulties, and loss of smell and taste [7].

Although, most patients have mild symptoms, some patients experience acute respiratory distress syndrome possibly that is generally attributed to cytokine storm. Severe disease can be complicated by septic shock, vascular thrombosis and multi-organ failure $[1,2,3]$.

Patients can infect others two days before the symptom onset and the disease can be transmitted from asymptomatic persons. Patients may remain infectious for seven to twelve days in moderate cases and up to two weeks in severe cases. The standard method for diagnosing the disease is real-time reverse transcription polymerase chain reaction (rRTPCR) from a nasopharyngeal swab $[4,5,6]$.

SARS-CoV-2 has already defeated the efforts to prevent its spread and caused probably the most global pandemic in history. SARS-CoV-2 continued to infect people and to take lives without the emergence of a treatment that is confirmed to have clinically a significant effectiveness in clinical treatment. The rational scientific approach to face a potentially fatal viral pandemic with no known effective specific therapies dictate the early use of all the useful preliminary research evidence with prioritizing emphasis on safety to avoid making more harm than good in such situation $[4,5,6]$.

\section{Patients and methods}

The treatment received by a patient "Donald Trump" who was considered the most powerful person in the world is studied, and this paper assumed that all the patients in the world are as important as Mr. Trump and tries to offer the best evidence-treatment for them.

\section{Results}

On Thursday, the first of October 2020, the White House of the USA declared that the president of the USA Donald Trump, his wife, and other White House officials had a positive test for SARS-CoV-2.

He aged 74 years and initially had mild symptoms which included mostly, hoarseness, lethargy, and fatigue. His age, obesity and mildly elevated cholesterol were considered risk factors that may reduce the likelihood of having very favorable outcome. It was reported that he initially took hydroxychloroquine, an anti-malarial drug.

In fact, during May, 2020 Mr. Trump reported that he has taken a twoweek-long preventive dose of hydroxychloroquine. On Friday, Trump developed fever, marked fatigue, difficulty in breathing with some lowering of oxygen saturation, a treatment with Regeneron's experimental cocktail of two monoclonal antibodies, and remdesivir (a five-day course) was started. He received $8 \mathrm{~g}$ intravenous infusion of Regeneron's mixture, which is the highest dose used in the treatment of 245 individual in an unpublished clinical trial conducted by Regeneron. Regeneron's antibodies were used to treat non-hospitalized patients to augment the immune response, and possibly reduce viral load.
Trump was Hospitalized for three days at Walter Reed National Military Medical Center, and left the hospital on Monday night. On Saturday, Trump needed supplemental because of the lowered oxygen saturation and he was given two doses of dexamethasone. On the second of October, Trump's doctors also reported that he was also receiving daily aspirin, melatonin, zinc, and famotidine.

Most media including the CNN television channel rightly confirmed that Mr. Trump has been treated by the best doctors in the world with best therapies that could possibly help him in defeating the virus. Dr Sean Conley (Figure-1) was probably the most important doctor who was in charge of the treatment of Mr. Trump.

In addition, the $\mathrm{CNN}$, in various programs during the first week of October, emphasized that, American citizens with Covid-19 are not receiving the same treatments as their president Donald Trump.

The use of a therapeutic approach including experimental antibody therapy, remdesivir and dexamethasone has not been reported as a treatment for one patient before other than Trump.

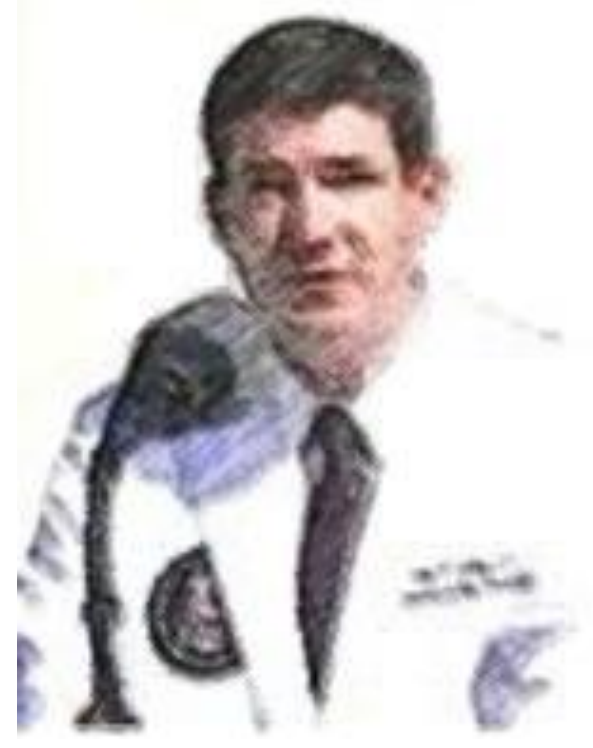

Figure-1: Dr Sean Conley, the most important doctor who was in charge of the treatment of Mr. Trump, was commonly described as one of the best doctors in the world. He had less than 10 scientific publications, and he dose not have an obvious score at his researchgate profile. He dose not have a profile at Scopus, Google Scholar Citation, nor dose have a profile at Semantic Scholar

Assuming that Mr. Trump is an ordinary man in this world, we will find, and that of the three medications that are considered most important, only dexamethasone can be offered to almost all the patients with covid19 throughout the world.

However, other medications, he received such as famotidine and melatonin are also generally available for most people in the world or can be easily available for most people.

Before Trump was tested positive, and considering him at a high risk, he received oral hydroxychloroquine as a preventive measure. Trump was possibly also receiving hydroxychloroquine very early during the time when tested positive for SARS-CoV-2.

However, because of the potential occurrence of side effect that demands regular medical supervision, we recommend the use of oral azithromycin $500 \mathrm{mg}$ tablets daily as a preventive measure. 
For positive asymptomatic patients, we recommend the use of oral azithromycin $500 \mathrm{mg}$ twice daily or oral azithromycin $500 \mathrm{mg}$ tablets daily plus low dose oral hydroxychloroquine $200 \mathrm{mg}$ once daily. For patients with positive test who have mild symptoms, it will be useful to add melatonin $5 \mathrm{mg}$ at night which will probably help with symptomatic control of cough and possibly help in the prevention of the cytokine storm.

When Trump developed the symptom of fever and difficulty of breathing treatment with remdesivir and Regeneron's antibody mixture was rapidly instituted before hospitalization. These two medications are generally not available for most patients throughout the world at this stage of illness.

Therefore, if Trump was an ordinary man in this world we recommend the following therapies at this stage:

1-Intravenous or intramuscular Teicoplanin in the doses suggested by Sato et al (2006) [4, 5, 6]. A loading dose of 400 or $800 \mathrm{mg}$ can be given on the first day, followed by maintenance dose of $400 \mathrm{mg}$.

2-Oral azithromycin $500 \mathrm{mg}$ twice daily.

3-Oral Famotidine.

4-Oral melatonin $5 \mathrm{mg}$ daily at night.

5 -Low dose of hydroxychloroquine $200 \mathrm{mg}$ can also be considered in patients with health hearts.

6-Dexamethasone can be given based on the clinical judgment.

Dr. Sean Conley said "Trump has also received dexamethasone, a cheap and widely available corticosteroid that can reduce inflammation. But it also suppresses the immune system, so it's generally not recommended for Covid-19 patients unless the situation is severe".

\section{Discussion}

Trump's was given Regeneron antibody mixture despite there was no published study describing its use. However, Regeneron press reported that experiments using golden hamsters and rhesus macaques that were intentionally infected with SARS-CoV-2 were associated with reduction of the viral levels and disease pathology. Regeneron reported that in an ongoing unpublished clinical trial in individuals (asymptomatic or have moderate) who tested positive for SARS-CoV-2, Antibody treatment reduced viral load and shortened symptomatic disease in patients who did not have SARS-CoV-2 antibodies at the initiation of the study. It was not possible to enroll Trump in the ongoing unpublished clinical trial because, it randomly assigns half the participants to receive the antibodies; while the other half of the patients are enrolled in the control group and receive infusions of an inactive placebo [7].

The United States Food and Drug Administration (FDA) regulation allows minor expanded access experimental treatments and treating physicians need to request what is called "A compassionate use" of an investigational new drug for individual patients or for emergencies [7].

Remdesivir is a drug that can be given intravenously and not orally. It has an anti-viral against several RNA viruses. It has an in vitro antiviral activity against filoviruses, arenaviruses, and coronaviruses including circulating human coronaviruses $\mathrm{HCoV}-\mathrm{OC} 43, \mathrm{HCoV}-229 \mathrm{E}$, SARS, and MERS zoonotic coronaviruses. Remdesivir (GS-5734) is a monophosphoramidate prodrug of an adenosine analogue that is activated intra-cellularly to the main metabolite in plasma "GS-441524" which acts mainly by interfering with the action of viral RNA-dependent RNA polymerase and escapes proofreading by viral exoribonuclease resulting reducing in viral RNA replication [1-8].

Warren et al (2016) reported that remdesivir has an antiviral activity against multiple variants of Ebola virus and other filoviruses in cell-based assays. Nonhuman primates receiving intravenous remdesivir had persistent nucleoside triphosphate levels in peripheral blood mononuclear cells (half-life:14 hours) and distribution to sites of viral replication in the testes, eyes, and brain. In a rhesus monkey model of Ebola virus disease, once-daily remdesivir intravenous administration of $10 \mathrm{mg} / \mathrm{kg}$ for 12 days was associated with a great suppression of Ebola virus replication and therefore protected $100 \%$ of Ebola virus-infected animals against fatal disease. Treatment also improved the clinical and pathophysiological markers, even when treatments were started three days after virus exposure when systemic viral RNA was detected in two out of six treated animals. Warren et al suggested that remdesivir important post-exposure protection against Ebola virus disease in nonhuman primates [9].

Sheahan et al (2017) showed that remdesivir can inhibit SARS-CoV and MERS-CoV replication in multiple in vitro systems, including primary human airway epithelial cell cultures with submicromolar $\mathrm{IC}_{50}$ values. Remdesivir can also inhibit bat $\mathrm{CoVs}$, pre-pandemic bat $\mathrm{CoVs}$, and circulating contemporary human $\mathrm{CoV}$ in primary human lung cells. In a mouse model of SARS-CoV pathogenesis, prophylactic and early therapeutic administration of remdesivir considerably decreased lung viral load and was associated with clinical improvement and also improved respiratory function [8].

Agostini et al (2018) reported that remdesivir can effectively inhibit human and zoonotic coronaviruses in vitro and in a severe acute respiratory syndrome coronavirus (SARS-CoV) mouse model. They also showed that remdesivir can inhibit murine hepatitis virus (MHV) with similar $50 \%$ effective concentration values $\left(\mathrm{EC}_{50}\right)$ as $\mathrm{SARS}-\mathrm{CoV}$ and Middle East respiratory syndrome coronavirus (MERS-CoV) [8].

In animal experiment, Pedersen et al (2019) studied the safety of remdesivir, and found it safe at a dose of $4.0 \mathrm{mg} / \mathrm{kg} \mathrm{S.C} \mathrm{q} 24 \mathrm{~h}$ for 12 weeks [10].

De Wit et al (2020) described the prophylactic and therapeutic use of remdesivir in the treatment of a nonhuman primate "rhesus macaque" model of MERS-CoV infection. Prophylactic remdesivir was started 24 hours before inoculation, completely prevented MERS-CoV-induced clinical disease, potently inhibited MERS-CoV replication in respiratory tissues, and prevented the formation of lung lesions. Therapeutic remdesivir treatment started 12 hours post-inoculation was associated with an obvious clinical benefit, with a reduction in clinical signs, reduced virus replication in the lungs, and reduction of lung lesions, and its severity [11].

Wang et al (2020) reported a randomised, double-blind, placebocontrolled, multicentre trial at ten hospitals in Hubei, China. The study included 237 adults with SARS-CoV-2 positive tests hospitalized within 12 days or less from the onset of symptoms and had oxygen saturation of $94 \%$ or less on room air or a ratio of arterial oxygen partial pressure to fractional inspired oxygen of $300 \mathrm{~mm} \mathrm{Hg}$ or less, and had radiological evidence of pneumonia. 158 patients were to remdesivir intravenous remdesivir (200 $\mathrm{mg}$ on day 1 followed by $100 \mathrm{mg}$ on days $2-10$ in single daily infusions). 79 patients were treated with placebo infusions for 10 days. Concomitant use of lopinavir-ritonavir, interferons, and corticosteroids was allowed.

Remdesivir use was not associated with a statistically significant difference in time to clinical improvement (hazard ratio 1.23 [95\% CI $0 \cdot 87-1 \cdot 75]$ ), but patients treated with remdesivir had a numerically faster time to clinical improvement than patients treated with placebo. Adverse effects were observed in $102(66 \%)$ of remdesivir-treated patients and 50 $(64 \%)$ of placebo-treated patients. Remdesivir was stopped early because of adverse effects in $18(12 \%)$ patients, and four (5\%) patients stopped placebo early [12].

Beigel et al (2020) reported a double-blind, randomized, placebocontrolled trial of treating adults hospitalized with Covid-19 with 
evidence of lower respiratory tract involvement with intravenous remdesivir. 538 patients were treated with remdesivir $(200 \mathrm{mg}$ loading dose on day 1 , followed by $100 \mathrm{mg}$ daily for up to 9 additional days). 521 patients were treated with placebo for up to 10 days. Remdesivir-treated patients had a median recovery time of 11 days ( $95 \%$ confidence interval [CI], 9 to 12), while patients in the placebo group had a median recovery time of 15 days (95\% CI, 13 to 19) [Rate ratio for recovery, 1.32; 95\% CI, 1.12 to $1.55 ; \mathrm{P}<0.001]$.

Kaplan-Meier mortality by 14 days were $7.1 \%$ in remdesivir-treated patients, and $11.9 \%$ the placebo group (hazard ratio for death, $0.70 ; 95 \%$ CI, 0.47 to 1.04). Serious effects occurred in 114 of the 541 patients in the remdesivir and 141 in the placebo group. Beigel et al considered remdesivir to be superior to placebo in shortening the time to recovery in adults hospitalized with Covid-19 who had lower respiratory tract infection [13].

The currently, available evidence suggests that remdesivir can be useful in the treatment of Covid-19, but its use as a mono-therapy is far from being the ultimate therapy for Covid-19. However, remdesivir was considered to be beneficial in the case of Trump because of its early use and because of the important fact that it was not used alone but in combination with other therapies [8].

Trump was also treated with dexamethasone rather early in course of the illness.

In a controlled, open-label trial hospitalized patients with Covid-19 were randomly assigned to receive oral or intravenous dexamethasone (at a dose of $6 \mathrm{mg}$ once daily) for up to 10 days or to receive usual care alone [14].

2104 patients received dexamethasone and 4321 received usual care. Overall, 482 patients $(22.9 \%)$ in the dexamethasone group and 1110 patients $(25.7 \%)$ in the usual care group died within 28 days after randomization (age-adjusted rate ratio, $0.83 ; 95 \%$ confidence interval [CI], 0.75 to $0.93 ; \mathrm{P}<0.001)$.

Patients treated with dexamethasone had lower incidence of death than that in the usual care group among patients receiving invasive mechanical ventilation ( $29.3 \%$ vs. $41.4 \%$; rate ratio, $0.64 ; 95 \%$ CI, 0.51 to 0.81$)$ and among those receiving oxygen without invasive mechanical ventilation ( $23.3 \%$ vs. $26.2 \%$; rate ratio, $0.82 ; 95 \%$ CI, 0.72 to 0.94 ) but not among those who were receiving no respiratory support at randomization $(17.8 \%$ vs. $14.0 \%$; rate ratio, 1.19 ; $95 \% \mathrm{CI}, 0.91$ to 1.55$)$.

This study suggested that the use of dexamethasone in patients hospitalized with Covid-19 can result in lower 28-day mortality among those who were treated with either invasive mechanical ventilation or oxygen alone at randomization but not among those receiving no respiratory support.

Chloroquine was thought to have an effect on SARS-CoV infection and spread which can be attributed to immunomodulatory effects, suppression of the production/release of TNF- $\alpha$ and IL-6, autophagy inhibition, and interference with the glycosylation of cellular receptors of SARS-CoV. Chloroquine may act on entry and at post-entry stages of the COVID-19 infection in Vero E6 cells [1-7].

As early as 2004, in vitro inhibition of severe acute respiratory syndrome coronavirus by chloroquine has been demonstrated by Keyaerts et al [15], and during February 2020, Gao, Tian, and Yang reported a benefit of chloroquine phosphate in SARS-CoV-2 associated pneumonia [16].

Azithromycin, a macrolide antibiotic is effective against rhinovirus, respiratory syncytial virus, and influenza virus [17, 18], and can also inhibit Zika and Ebola viruses [19, 20]. Tran et al. indicated that influenza progeny virus replication was remarkably inhibited by treating influenza virus with azithromycin before infection $[4,5,6,7]$.

A study treated two groups of SARS-CoV-2 patients and compared the effect of treatment with sixteen SARS-CoV-2 control patients. Six patients (First group) were treated with hydroxychloroquine $(200 \mathrm{mg}, 3$ times daily, for 10 days) plus azithromycin ( $500 \mathrm{mg}$ on first day, followed by $250 \mathrm{mg}$ daily for the next 4 days), 14 patients were treated with hydroxychloroquine as a single drug. On the sixth day of treatment, $100 \%$ of patients treated with hydroxychloroquine plus azithromycin (First group) experience virological cure. Only $57.1 \%$ of the patients treated with hydroxychloroquine as a single drug (Second group) and $12.5 \%$ in the control group experienced virological cure $(P<0.001)$. Thereafter, one patient, who was treated with hydroxychloroquine as a single drug (in the second group) and continued to have PCR-positive at the sixth day of treatment, received azithromycin, and experience a virological cure [21].

The recent use of Famotidine, a class A G protein-coupled receptor antagonist in SARS-CoV2 has been associated with a good outcome. The combined use of famotidine and hydroxychloroquine has been suggested and is currently being tested in an ongoing clinical trial in the United States. In the 1990s, the use of famotidine as an antiviral agent against human immunodeficiency virus (HIV) has been suggested. The antiviral effect of famotidine has been attributed to the inhibition of proteases involved in the virus replication because it can interact within the catalytic site of the three proteases associated with SARS-CoV2 replication. However, weak binding affinity of famotidine to the three proteases makes successful famotidine therapy more likely when combined with other antiviral drugs and when given intravenously [22, 23].

Hogan et al (2020) reported a physician-sponsored cohort study of the use of cetirizine (10 $\mathrm{mg}$ b.i.d.) and famotidine (20 mg b.i.d,) in 110 covid-19 hospitalized patients with severe to critical respiratory symptoms. Patients also received standard-of-care. Treatment was associated with a $16.4 \%$ rate of intubation, a $7.3 \%$ rate of intubation after a minimum of 48 hours of treatment, a $15.5 \%$ rate of inpatient mortality, and 11.0 days duration of hospitalization. Treatment was also associated with beneficial lowering of inpatient mortality and progression of symptoms when compared to previously reported cases of COVID-19 inpatients. Concomitant use of hydroxychloroquine was associated with worse outcomes. Hogan et al suggested that the use of cetirizine and famotidine can be a safe and effective strategy to reduce the progression in symptom severity, possibly by minimizing the histamine-mediated cytokine storm [24].

Mather, Seip, and McKay (2020) reported a retrospective, propensitymatched observational study which included 878 consecutive COVID-19 patients observed during the period from February 24, 2020, and May 13, 2020. The study aimed at comparing the outcomes in hospitalized covid19 patients receiving famotidine therapy (83 patients, $9.5 \%$ ) with patients not receiving famotidine. Famotidine treated patients were younger (63.5 \pm 15.0 vs $67.5 \pm 15.8$ years, $\mathrm{P}=0.021$ ), but the two groups did not differ with in baseline demographics and preexisting co-morbidities. Famotidine treatment was associated with a lower risk of in-hospital mortality (odds ratio $0.37,95 \%$ confidence interval $0.16-0.86, \mathrm{P}=0.021$ ) and combined death or intubation (odds ratio $0.47,95 \%$ confidence interval $0.23-0.96, \mathrm{P}=0.040$ ). Patients treated with received famotidine also had lower levels of serum markers for severe disease including lower median peak C-reactive protein levels ( 9.4 vs $12.7 \mathrm{mg} / \mathrm{dL}, \mathrm{P}=0.002)$, and lower median procalcitonin levels ( 0.16 vs $0.30 \mathrm{ng} / \mathrm{mL}, \mathrm{P}=0.004$ ) [25].

Janowitz et al (2020) reported a study using oral famotidine in 10 covid19 non- hospitalized patients. Most frequently, famotidine was given in a dose of $80 \mathrm{mg}$ three times daily $(\mathrm{n}=6)$ for a median of 11 days (range: 5 21 days). Treatment was well tolerated, and the ten patients reported marked improvements of symptoms after starting famotidine. The combined symptom score markedly improved within 24 hours of starting 
famotidine and peripheral oxygen saturation $(n=2)$ and device recorded activity $(n=1)$ also increased [26].

Freedberg et al (2020 reported a retrospective study which included 1620 covid-19 hospitalized patients with, 84 patients $(5.1 \%)$ received famotidine within 24 hours of hospital admission. The use of famotidine was associated with a reduced risk of clinical deterioration leading to intubation or death [27].

Baron et al (2020) emphasized that teicoplanin was previously reported to be effective in inhibiting the first stage of MERS-coronarivus viral cycle in human cells, was also active against the SARS-Cov-2 [28].In addition, Wang et al (2016) teicoplanin can inhibit Ebola pseudovirus infection by blocking virus entry in the low micromolar range [29]. It is also able to block the MERS and SARS envelope pseudotyped viruses.

Teicoplanin is a semi-synthetic glycopeptide antibiotic used in the prophylaxis and treatment of serious infections caused by Gram-positive bacteria, including methicillin-resistant Staphylococcus aureus and Enterococcus faecalis. It acts by inhibiting bacterial cell wall synthesis, and its spectrum of activity similar to vancomycin. Oral teicoplanin has been shown to be effective in the treatment of pseudomembranous colitis and Clostridium difficile-associated diarrhea, with comparable efficacy with vancomycin [1-7].

Teicoplanin can be used in the doses suggested by Sato et al (2006) [30]. A loading dose of 400 or $800 \mathrm{mg}$ can be given on the first day, followed by maintenance dose of $400 \mathrm{mg}$. In areas where serial tests are available for asymptomatic patients, a dose of $400 \mathrm{mg}$ can be given for to days with aim of achieving early negative test and clearance of the virus, and thus reducing its spread.

There is some preliminary evidence relying on data on homogenous coronaviruses and other pathogens suggesting that reducing the excessive inflammation, oxidation, and an exaggerated immune response which may contribute to SARS-CoV-2 pathological changes including a cytokine storm and progression to acute lung injury/acute respiratory distress syndrome and even death, may contribute to improving the outcome.

In respiratory syncytial virus mice models, the use of melatonin was reported to cause down regulation of pro-inflammatory cytokine release, acute lung oxidative injury, and inflammatory cell activation. Melatonin, a safe, well-known anti-inflammatory and anti-oxidative molecule, is protective against severe respiratory symptoms caused by viruses and other pathogens. Melatonin was effective in critical care patients, probably acting by reducing vessel permeability, anxiety, sedation use, and improving sleeping quality. There is acceptable evidence suggesting that melatonin can limit virus-related diseases that enable its recommendation in the adjunctive supportive therapies [5, 6, 7].

A recent evidence-based recommendation which was published in 9 languages [5, 6, 31-38] emphasized that until now, there is no single drug can result in a virological cure.

The early use of safe well-known therapeutic agents having the potential to control the virus such as azithromycin, and teicoplanin can help in preventing milder cases from spreading the virus, and also may prevent the progression to serious pneumonia and significant respiratory distress. However, effective treatment for more severe cases can also be achieved by the early use of drug combinations that may include Azithromycin+ teicoplanin + famotidine, remdesivir + azithromycin, + teicoplanin. The addition of low dose chloroquine can also be considered in patients with healthy hearts [7].

\section{Conlusion}

It seems that, the most important factors that made treatment of Donald Trump effective and successful are:

1-The early institution of therapy regardless of the generally accepted recommendations.

2-The use of multiple drugs as none of the available drug alone can guarantee successful treatment.

\section{Recommendation}

Assuming that all patients in the world are as important as Mr. Trump and offering them the best evidenced-based therapies as early as possible.

We recommend the use of oral azithromycin $500 \mathrm{mg}$ tablets daily as a preventive measure for high risk individuals.

We recommend the use of oral azithromycin $500 \mathrm{mg}$ twice daily or oral azithromycin $500 \mathrm{mg}$ tablets daily plus low dose oral hydroxychloroquine $200 \mathrm{mg}$ once daily for asymptomatic patients who tested positive.

For patients with positive test who have mild symptoms, it will be useful to add melatonin $5 \mathrm{mg}$ at night which will probably help with symptomatic control of cough and possibly help in the prevention of the cytokine storm.

For patients with difficulty in breathing who don't have the access to treatment with remdesivir and Regeneron's antibody mixture, we recommend early use of the following therapies at this stage:

1-Intravenous or intramuscular Teicoplanin in the doses suggested by Sato et al (2006) [4, 5, 6, 7]. A loading dose of 400 or $800 \mathrm{mg}$ can be given on the first day, followed by maintenance dose of $400 \mathrm{mg}$.

2-Oral azithromycin $500 \mathrm{mg}$ twice daily.

3-Oral Famotidine.

4-Oral melatonin $5 \mathrm{mg}$ daily at night.

5-Low dose of hydroxychloroquine $200 \mathrm{mg}$ can also be considered in patients with health hearts.

6-Dexamethasone can be given based on the clinical judgment.

\section{Acknowledgement}

The sketch in figure-1 was published before in our previous publication and the author has their copyright.

\section{Conflict of interest: None}

\section{References}

1. Al-Mosawi AJ. (2020) Bat-Human Coronaviruses: A Global Health Problem and a Therapeutic Challenge. Journal of Medical Clinical Case Reports. 2(2) 1-3.

2. Al-Mosawi AJ. (2020) Bat-human coronaviruses: Keys to the therapeutic challenge. $1^{\text {st }}$ ed., Saarbrücken; LAP Lambert Academic Publishing.

3. Al-Mosawi AJ. (2020) Bat-human Coronaviruses: Keys to The Therapeutic Challenge $.1^{\text {st }}$ ed., Baghdad; Iraq Headquarter of Copernicus Scientists International Panel Publishing.

4. Al-Mosawi AJ. The Use of the Available Research Evidence to Crack the Padlock of Sars-CoV-2. Journal of Virology Research \& Reports. 1 (1):1-8

5. Al-Mosawi AJ. (2020) Using research evidence to crack the padlock of SARS-CoV-2. $1^{\text {st }}$ ed., LAP Lambert Academic Publishing, Saarbrücken; Germany.)

6. Al-Mosawi AJ. (2020) The use of the available research evidence to crack the padlock of SARS-CoV-2.1 ${ }^{\text {st }}$ ed., 
Baghdad; Iraq Headquarter of Copernicus Scientists International Panel Publishing.

7. Al-Mosawi AJ. (2020) Trump's covid-19 treatment: Is there any better approach? Scholar's press.

8. Al-Mosawi AJ. (2020) Remdesivir research progress: An overview of the emerging evidence. Biomedical Research \& Environmental Sciences. 6(10): 216-218.

9. Warren TK, Jordan R, Lo MK, et al. (2016) Therapeutic efficacy of the small molecule GS-5734 against Ebola virus in rhesus monkeys [published correction appears in ACS Chem Biol. 11(5):1463]. Nature 2016; 531(7594):381-385. PMID: 26934220

10. Pedersen NC, Perron M, Bannasch M, et al. (2019) Efficacy and safety of the nucleoside analog GS-441524 for treatment of cats with naturally occurring feline infectious peritonitis. J Feline Med Surg. 21(4):271-281. PMID: 30755068.

11. de Wit E, Feldmann F, Cronin J, et al. (2020) Prophylactic and therapeutic remdesivir (GS-5734) treatment in the rhesus macaque model of MERS-CoV infection. Proc Natl Acad Sci USA. 117(12):6771-6776. PMID: 32054787.

12. Wang Y, Zhang D, Du G, et al. (2020) Remdesivir in adults with severe COVID-19: a randomised, double-blind, placebocontrolled, multicentre trial [published correction appears in Lancet. 395(10238):1694]. Lancet 2020; 395(10236):15691578. PMID: 32423584.

13. Beigel JH, Tomashek KM, Dodd LE, et al. (2020) Remdesivir for the Treatment of Covid-19 -Preliminary Report [published online ahead of print, 2020 May 22]. N Engl J Med. NEJMoa2007764. PMID: 32445440.

14. RECOVERY Collaborative Group, Horby P, Lim WS, Emberson JR, Mafham M, Bell JL, Linsell L, Staplin N, Brightling C, Ustianowski A, Elmahi E, Prudon B, Green C, Felton T, Chadwick D, Rege K, Fegan C, Chappell LC, Faust SN, Jaki T, Jeffery K, Montgomery A, Rowan K, Juszczak E, Baillie JK, Haynes R, Landray MJ. Dexamethasone in Hospitalized Patients with Covid-19 - Preliminary Report. N Engl J Med. NEJMoa2021436. PMID: 32678530.

15. Keyaerts E, Vijgen L, Maes P, Neyts J, Van Ranst. (2004) In vitro inhibition of severe acute respiratory syndrome coronavirus by chloroquine. Biochemical and Biophysical Research Communications 323 (1): 264-8. PMID: 15351731.

16. Gao J, Tian Z, Yang X. Breakthrough: Chloroquine phosphate has shown apparent efficacy in treatment of COVID-19 associated pneumonia in clinical studies. Bioscience Trends. 14: 72-73. PMID: 32074550.

17. Min JY, Jang YJ. (2012) Macrolide therapy in respiratory viral infections. Mediators Inflamm. 2012:649570.

18. Tran DH, Sugamata R, Hirose T, et al. (2019) Azithromycin, a 15-membered macrolide antibiotics, inhibits influenza $A$ (H1N1) pdm09 virus infection by interfering with virus internalization process. J Antibiot (Tokyo) 72:759-768.

19. Bosseboeuf E, Aubry M, Nhan T, Pina JJ, Rolain JM, Raoult D, Musso D. (2018) Azithromycin inhibits the replication Zika virus. J Antivir Antietrovir. 10:6-11.

20. Madrid PB, Panchal RG, Warren TK, Shurtleff AC, Endsley AN, Green CE, Kolokoltsov A, Davey R, Manger ID, Gilfillan L, Bavari S, Tanga MJ. (2015) Evaluation of Ebola virus inhibitors for drug repurposing. ACS Infect Dis. 1:317-326.

21. Gautret P, Lagier JC, Parola P, et al. (2020) Hydroxychloroquine and azithromycin as a treatment of COVID-19: results of an open-label non-randomized clinical trial. Int J Antimicrob Agents 20:105949.

22. Sen Gupta PS, Biswal S, Singha D, Rana MK. (2020) Binding insight of clinically oriented drug famotidine with the identified potential target of SARS-CoV-2. J Biomol Struct Dyn. 1-7. PMID: 32579065.

23. Ortega JT, Serrano ML, Jastrzebska B. (2020) Class A G Protein-Coupled Receptor Antagonist Famotidine as a Therapeutic Alternative Against SARS-CoV2: An In Silico Analysis. Biomolecules. 10(6):954. PMID: 32599963.

24. Hogan Ii RB, Hogan Iii RB, Cannon T, Rappai M, Studdard J, Paul D, Dooley TP. (2020) Dual-histamine receptor blockade with cetirizine - famotidine reduces pulmonary symptoms in COVID-19 patients. Pulm Pharmacol Ther. 63:101942. PMID: 32871242.

25. Mather JF, Seip RL, McKay RG. (2020) Impact of famotidine use on clinical outcomes of hospitalized patients with covid-19. Am J Gastroenterol. 115(10):1617-1623. PMID: 32852338.

26. Janowitz T, Gablenz E, Pattinson D, Wang TC, Conigliaro J, Tracey K, Tuveson D. (2020) Famotidine use and quantitative symptom tracking for COVID-19 in non-hospitalised patients: a case series. Gut. 69(9):1592-1597. PMID: 32499303.

27. Freedberg DE, Conigliaro J, Wang TC, Tracey KJ, Callahan MV, Abrams JA .(2020) Famotidine Research Group. Famotidine Use Is Associated With Improved Clinical Outcomes in Hospitalized COVID-19 Patients: A Propensity Score Matched Retrospective Cohort Study. Gastroenterology. 159(3):1129-1131.e3. PMID: 32446698.

28. Baron SA, Devaux C, Colson P, Raoult D, Rolain JM. (2020) Teicoplanin: an alternative drug for the treatment of coronavirus COVID-19? Int J Antimicrob Agents. 105944. PMID: 32179150.

29. Wang Y, Cui R, Li G, Gao Q, Yuan S, Altmeyer R, Zou G. (2016) Teicoplanin inhibits Ebola pseudovirus infection in cell culture. Antiviral Res. 125:1-7. PMID: 26585243.

30. Sato M, Chida K, Suda T, Muramatsu H, Suzuki Y, Hashimoto H, Gemma H, Nakamura H. (2006) Recommended initial loading dose of teicoplanin, established by therapeutic drug monitoring, and outcome in terms of optimal trough level. J Infect Chemother. 12(4):185-9. PMID: 16944256.

31. Al-Mosawi AJ. (2020) Использование данных исследований для взлома замка SARS-CoV-2 (Russian edition) Sciencia Scripts:

32. Al-Mosawi AJ. (2020) Utilização de provas de investigação para rachar o cadeado da SRA-CoV-2 (Portuguese edition) .Edições Nosso Conhecimento.

33. Al-Mosawi AJ. (2020) Użycie dowodów naukowych do złamania kłódki SARS-CoV-2 (Polish edition) Wnictwo Nasza Wiedza:

34. Al-Mosawi AJ. (2020) Gebruik van onderzoeksmateriaal voor het kraken van het hangslot van SARS-CoV-2 (Dutch edition). Uitgeverij Onze kennis.

35. Al-Mosawi AJ. (2020) Utilizzare le prove della ricerca per rompere il lucchetto della SARS-CoV-2 (Italian edition) Edizioni Sapien.

36. Al-Mosawi AJ. (2020) Utilisation des résultats de la recherche pour briser le cadenas du SRAS-CoV-2 (French edition) Editions Notre Savoir.

37. Al-Mosawi AJ. El uso de pruebas de investigación para romper el candado del SARS-CoV-2 (Spanish edition). Ediciones Nuestro Conocimiento.

38. Al-Mosawi AJ. (2020) Verwendung von Forschungsergebnissen zum Knacken des Vorhängeschlosses von SARS-CoV-2 (German edition). Verlag Unser Vissen. 